Part of Journal of Research of the National Bureau of Standards, Volume 33, November 1944

\title{
IMPROVED REFLUX REGULATOR AND HEAD FOR LABORATORY DISTILLING COLUMNS ${ }^{1}$
}

\author{
By Charles B. Willingham ${ }^{2}$, and Frederick D. Rossini
}

\section{ABSTRACT}

A reflux regulator and head for laboratory distilling columns is described that is an improvement over the one previousiy in use (see J. Research N. B. S. 23, 509 (1939) RP1249) in the distillation laboratory at the National Bureau of Standards in connection with the work of the American Petroleum Institute Research Project 6 . The improvements are in better measurement of the temperature of the liquid-vapor equilibrium, in reduction of the hold-up, and in increase in the mechanical strength.

CONTENTS

I. Introduction

II. Apparatus

III. Discussion

IV. References

\section{INTRODUCTION}

A reflux regulator and head for laboratory distilling columns that was used through 1943 in the distillation laboratory at the National Bureau of Standards in connection with the work of the American Petroleum Institute Research Project 6 was previously described [1]. ${ }^{3}$ Because of the then limited height (135 inches) in the distillation laboratory, the previously described head was so designed as to require a minimum of space (about 6 inches) between the ceiling and the top of the packing in the rectifying section of the distilling column. This requirement was met by means of certain compromises in design that were no longer necessary when the laboratory was moved at the end of 1943 to a new location having a ceiling height of about 320 inches. This paper describes the improved reflux regulator and head for laboratory distilling columns for use in locations having adequate height. The improvements are in better measurement of the temperature of the liquid-vapor equilibrium, in reduction of the hold-up, and in increase in mechanical strength.

\footnotetext{
1 This investigation is part of the work of Research Project 6 of the American Petroleum Institute, from whose research fund financial assistance has been received.

${ }^{2}$ Research Associate at the National Bureau of Standards, representing the American Petroleum Institute.

${ }_{3}$ The figures in brackets indicate the literature references at the end of this paper.
} 


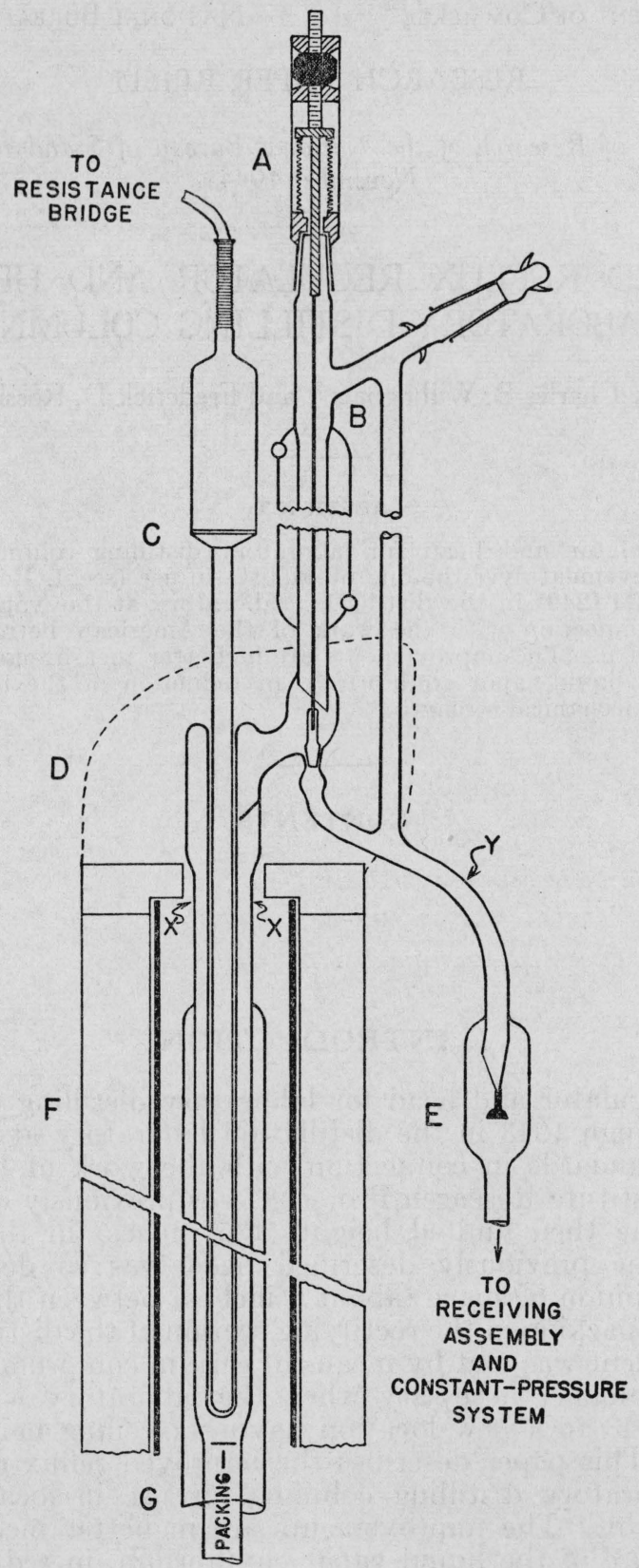

Figure 1.-Assembly of reflux regulator and head.

$A$, Metal housing and control, with metallic bellows, as described in figure 3 of reference [1]; $B$, Pyrexglass part of the apparatus, as shown in figure 2 of this paper; $C$, platinum-resistance thermometer (a thermoelement or other thermometer may be used); $D$, boundary of the thermal insulation on the finished head; $E$, drop counter, with dimensions as shown in figure 2 of reference [1]; $F$, top of jacket assembly; $G$, top of rectifying section, showing vacuum jacket; $X, Y$, places where the glass head (as shown in figure 2 of this paper) is sealed to the rectifying section and to the drop counter, respectively. 


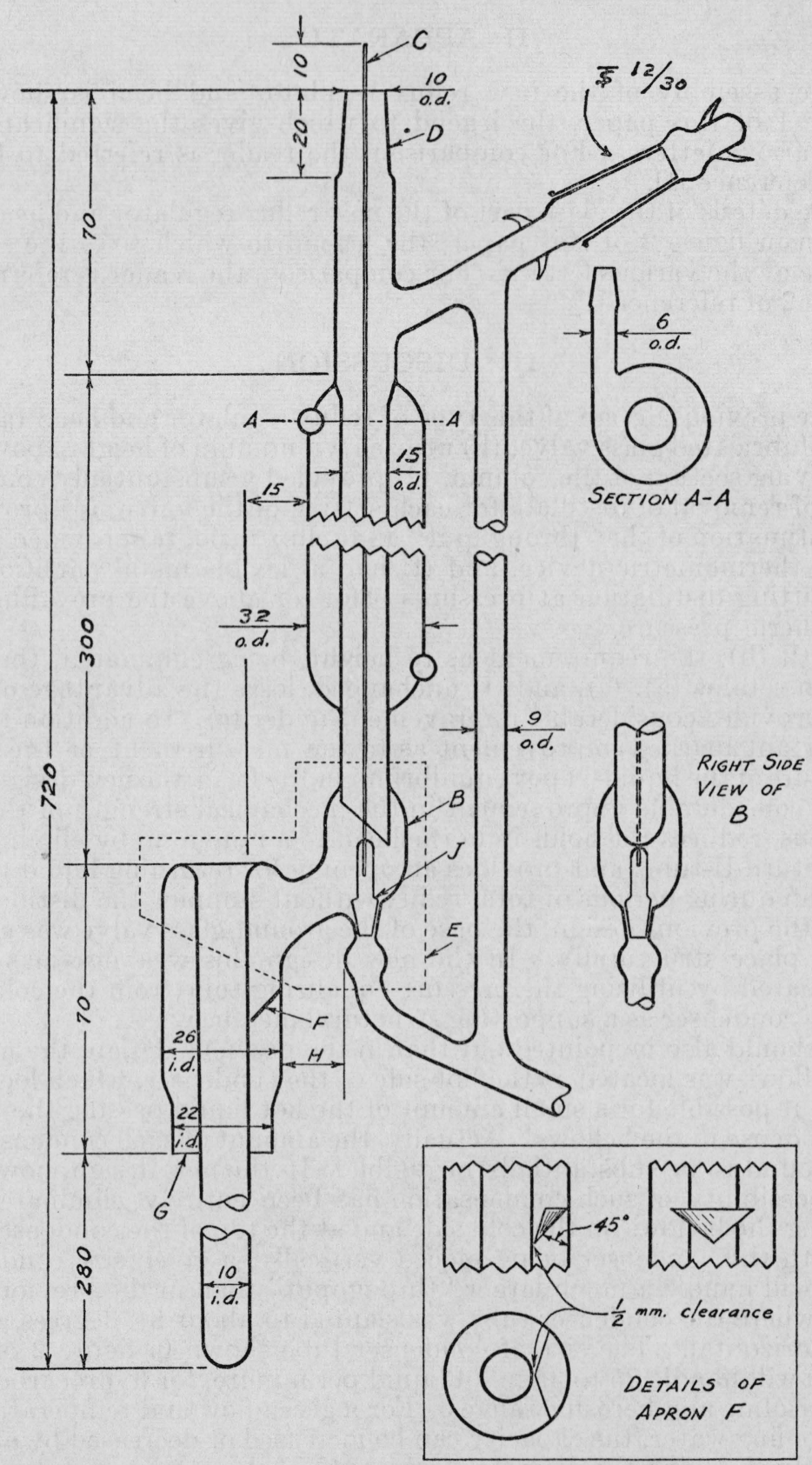

FIGURE 2.-Details of the glass part of the apparatus.

$A$, Section showing"opening in jacket of condenser; $B$, portion connecting condenser with ground-glass valve; $C$, tungsten rod, No. $12 \mathrm{AWG} ; D$, male ground joint, standard taper, $12 / 20 ; E$, portion having extraheavy wall; $F$, apron to direct liquid from the condenser to the thermometer well; $G$, bottom edge for sealing to rectifying tube (should be smooth and have its plane perpendicular to the axis of the thermometer well); $H$, clearance (to be not less than $15 \mathrm{~mm}$ ); $J$, ground-glass valve, taper 1 in 5 , small end $4 \mathrm{~mm}$, large end $6 \mathrm{~mm}$, length $10 \mathrm{~mm}$, ground for high vacuum. Pyrex laboratory glass; entire assembly to be thoroughly annealed. Note: All dimensions in millimeters. 


\section{APPARATUS}

The assembly of the new reflux regulator and head is shown in figure 1 of this paper, the legend to which gives the significance of the various letters. For comparison, the reader is referred to figure 1 of reference [1].

The details of the glass part of the new reflux regulator and head are shown in figure 2 of this paper, the legend to which gives the significance of the various letters. For comparison, the reader is referred to figure 2 of reference [1].

\section{DISCUSSION}

The previous design of this type of reflux regulator and head (a) had a nonlubricated glass valve, (b) utilized a minimum of height above the rectifying section of the column, (c) provided a substantially constant rate of removal of distillate for each setting of the valve, (d) provided for estimation of the "throughput" and reflux ratio, (e) provided space for a thermometric device, and (f) had a flexible metal partition for permitting distillation at pressures below or above the prevailing atmospheric pressure.

With (b), the requirement as to height, being eliminated, the new design retains (a), (c), and (f) unchanged, loses the advantage of (d), and provides considerable improvement under (e). In addition to the important marked improvement as to the measurement of the temperature of the liquid-vapor equilibrium in the head, the new design provides considerable improvement in the mechanical strength of the apparatus, reduces the hold-up in the head to a minimum by eliminating the return $U$-tube, and provides an opening for returning liquid to the column during periods of total reflux without stopping the distillation.

In the previous design, the base of the ground-glass valve was a very weak place structurally. In the new design this weakness has been eliminated by utilizing the pressure-equalizing tube from the cold end of the condenser as a supporting structural member.

It should also be pointed out that in the previous design, the metallic bellows was located at the hot side of the condenser, which location made it possible for a small amount of the hot liquid passing the valve to condense in the bellows. Actually, the amount of such condensation was found to be substantially negligible. In the new design, however, the possibility of such condensation has been entirely eliminated by placing the bellows on the cold side and at the top of the condenser.

With the condenser being placed vertically, a given size condenser tube will handle a much larger "throughput" than in the previous design, where the condenser tube was slanted to about $8 \frac{1}{2}$ degrees above the horizontal. The size of condenser tube shown in figure 2 of this paper will handle 25 to $35 \mathrm{ml}$ of liquid per minute, for hydrocarbons of the gasoline and kerosine ranges. For a given flow and temperature of the cooling water, the capacity can be increased or decreased by appropriately changing the diameter and length of the condenser tube. For use in this laboratory, a larger size, to handle 40 to $60 \mathrm{ml}$ of liquid per minute, has been made with changes in the dimensions of the condenser, as follows: Length of condenser tube, increase from 300 to 360 $\mathrm{mm}$; diameter of inner and outer tubes of condenser, increase from 15 to $18 \mathrm{~mm}$ and from 32 to $35 \mathrm{~mm}$, respectively. 
In connection with the measurement of the temperature of the liquidvapor equilibrium in the head, the new design provides space for a 25ohm platinum resistance thermometer, with adequate depth of immersion, the thermometer proper being actually well down inside the vacuum-jacketed part of the rectifying section. If it is desired to use a multiple junction thermoelement for the measurement of temperature, both the diameter and length of the thermometer well can be decreased.

An indication of the adequacy of the provision for the thermometer is provided by the fact that in a distilling column arranged as shown in figure 1 , with a platinum resistance thermometer and with the pressure controlled (near $725 \mathrm{~mm}$ ) constant to $\pm 0.2 \mathrm{~mm} \mathrm{Hg}$, the readings of temperature taken hourly showed normal variations of not more than $\pm 0.01^{\circ} \mathrm{C}$, for periods up to 200 hours, when a pure compound was distilled [2].

\section{REFERENCES}

1] F. D. Rossini and A. R. Glasgow, Jr., J. Research NBS 23, 509 (1939) RP1249.

[2] C. B. Willingham and F. D. Rossini, National Bureau of Standards. Unpublished data.

Washington, August 15, 1944. 